\title{
TRIAL COURTS: \\ AN ECONOMIC PERSPECTIVE
}

\author{
ROBERT D. COOTER \\ DANIEL L. RUBINFELD
}

\begin{abstract}
This article describes economic research on models of legal disputes. Concepts such as rational choice and static equilibrium are often used inaccurately in the noneconomic research presented in this issue. This article critiques the longitudinal studies, illustrating a number of problems of conceptualization and data analysis. Finally, the authors consider normative models of dispute resolution and the evolution and effects of judge-made law.
\end{abstract}

Longitudinal studies of trial courts like those reported in this issue often fail to test hypotheses conclusively for want of rigorous specification. In contrast, economic analysis (which has been applied to courts only recently) is rigorous, but its theoretical insights have run far ahead of statistical testing. This article is written by two economists who believe that rigorous theories must be combined with data in order to obtain a thorough understanding of courts. The article's aim is to build a bridge that brings the economic literature into contact with the longitudinal studies. Toward this end, Part I describes economic research on positive models of legal disputes. ${ }^{1}$ As a careful reader of this review will note, elements of these positive models-for example, the concepts of rational choice and static equilibrium-are implicit in the noneconomics research on courts, litigation, and dispute processing. In noneconomics research the treatment of concepts to which economists would attempt to give a precise theoretical meaning is often unsystematic or imprecise. Therefore, Part II critiques the longitudinal studies in this issue from an economist's point of view, illustrating problems of conceptualization and data analysis that arise from failure to make an underlying model more precise. We

Daniel Rubinfeld acknowledges financial support from the National Science Foundation, Program in Law and Social Science, and the John M. Olin Foundation.

1 For a more technical, detailed review of the economics literature, see Cooter and Rubinfeld (1989).

LAW \& SOCIETY REVIEW, Volume 24, Number 2 (1990) 
suggest how the research might have been approached to avoid such problems. Finally, Part III considers longitudinal research issues examined by economists that are not addressed anywhere else in this issue, namely, normative models of dispute resolution and the evolution and effects of judge-made law.

\section{POSITIVE MODELS OF LEGAL DISPUTES}

A legal dispute can be divided into distinct stages for purposes of analysis. In the beginning there is an underlying event, such as an accident or crime, in which one person (the injurer) allegedly harms another (the victim). In the second stage, the victim or the state asserts a legal claim against the injurer. A dispute arises when there is disagreement over the claim. The dispute acquires a formal character in its third stage, which encompasses a sequence of acts precedent to a trial, such as filing a formal complaint, replying to the complaint, attending a preliminary hearing, engaging in pretrial discovery, and setting a trial date. During this formal process the court usually encourages the parties to settle their dispute through bargaining. If bargaining fails, the fourth and final stage is reached when the case is taken to court. At trial each side tries to win rather than to reach a compromise. After trial, the court announces its decision, and the parties decide whether to appeal.

Having distinguished these stages, our next task is to model them. The injurer allegedly harms the victim in the first stage of a legal dispute. The harm may be intentional as in the case of most crimes, accidental as in the case of many torts, or incidental as in many nuisance situations. In any case, the behavior of injurers and, in some cases, victims (their levels of activity and the precaution that they take) affect the frequency and extent of harm to one or both parties.

Although harm is a social cost, curtailing it is costly in itself. For example, automobile accidents harm people, but driving less prevents valuable trips and driving slower uses valuable time. As a result, economic efficiency requires balancing the cost of harm against the cost of avoiding it (and more generally the costs of risk bearing).

The way the balancing gets done depends on whether or not the parties have a contractual relationship prior to the harm's occurrence. To illustrate, suppose that a manufacturer can affect a product's dangerousness through quality control, the law permits the parties to allocate liability for injuries by private agreement, and the buyer is fully aware of both the danger and the liability. In these circumstances, the buyer's willingness to pay for the manufactured good will be discounted by the full extent of the losses that he expects to bear. (The "externality" will be "internalized" by the market.) If, however, the injurer and victim have no mar- 
ket relationship, as with a driver and an anonymous pedestrian, there is no scope for them to reallocate liability by private agreement. These two examples-perfect markets and no markets-can be regarded as polar cases in which the transaction costs (the costs of communicating and bargaining to reach agreement) of reallocating liability are zero at one pole and prohibitively large at the other pole.

The economics literature usually assumes that law has little effect on activities and precaution so long as the transaction costs of reallocating liability are low. (This is a version of the famous Coase theorem.) $)^{2}$ Law can have little effect under these circumstances because private parties will restructure liability by private agreement in the way that is most advantageous to them. When transaction costs are large, however, the potential injurers and victims cannot contract around the initial allocation of liability by law. Under these conditions the legal allocation of liability affects the parties' activities and precaution. The economic models assume that behavior responds predictably to material incentives. Crimes can be deterred, activities can be curtailed, and precaution can be induced by increased exposure to liability or punishment. Thus, the sign of the response is assumed by the economic models, but its magnitude must be measured empirically, which corresponds to assuming a priori that the supply curve has a positive slope and then measuring its elasticity econometrically. To illustrate, making injurers liable for the harm that they accidentally cause creates incentives to curtail activities and increase precaution; the extent of these responses must be measured empirically.

Economists measure the "supply" of social harm much the way they measure the supply of an ordinary good. ${ }^{3}$ Of course, legal incentives are not the only determinants of the level of harm. Important socioeconomic determinants are largely independent of the liability system. For example, automobile accident litigation may be affected by automobile registrations, gasoline prices, the average age of drivers, income levels, and urbanization. In the econometric approach, therefore, the supply of activities and precaution is the dependent variable in a regression analysis in which independent variables are the prices and constraints given by the legal system and socioeconomic variables. Thus, economists have taken this approach to explaining changes in accidents rates result-

2 The Coase theorem is usually stated something like, "The legal allocation of rights does not matter from the viewpoint of economic efficiency so long as no obstacles hinder their exchange." The theorem is suggested, but not explicitly stated, in Coase (1960).

3 An important distinction is whether or not victims and injurers act strategically with respect to each other. To illustrate, the care I take in crossing the street does not influence the care taken by drivers, so I need not act strategically. Alternatively, a manufacturer may believe that greater safety in the design of machinery will cause workers to take less care when using it, in which case the manufacturer will act strategically. 
ing from a switch to no-fault laws of liability (Grayston, 1973; Landes, 1982; Devlin, 1989).

If empirical research on the litigation system omits some of these endogenous and exogenous variables, it will be inconclusive. To illustrate, social scientists in the alternative dispute resolution movement are eager to find ways of reducing the number of trials by adopting rules or practices that encourage settlements. Some types of disputes are easier to settle than others. Many legal institutions or rules affect both the types of disputes and the ease of settling them. Longitudinal studies of litigation rates must disentangle an increase in the probability of settling a particular kind of dispute from an increase in the proportion of easily settled disputes. Furthermore, longitudinal studies must correct for changes in socioeconomic variables that occur spontaneously with the passage of time. Economic theories facilitate empirical research aimed at disentangling these effects by identifying the relevant variables to be measured and predicting their signs.

Having discussed the underlying acts precedent to suits, we move to the next stage in the chronology of a dispute during which a legal claim is made. A rationally self-interested person decides whether to press a claim by asking whether the cost of going forward exceeds the expected payoff. (See, among others, Shavell, 1982; Posner, 1986: chap. 21.) The initial cost of going forward is the time, effort, and legal fees required to complain. The expected payoff from pressing a claim depends upon the possible outcomes of settlement bargaining and, in the event bargaining fails, of a trial. Thus the expected payoff from pressing a claim is affected by legal rules that allocate litigation costs, assign the burdens and standards of proof, and specify the basis for computing damages. For example, the rule in the United States that each side pays its own litigation expenses increases the willingness of potential plaintiffs to press claims with a small probability of winning a large sum of money. (A similar argument applies to contingent fees and punitive damages). In contrast, small probability suits are discouraged by the British and continental institutions that require the loser to pay the winner's litigation costs, forbid contingent fees, and do not allow punitive damages. ${ }^{4}$

To go forward with a claim, the victim must engage a lawyer. Plaintiffs possess rights of action, and lawyers possess the information needed to assess their worth. The plaintiff is the principal and the lawyer is the agent. Their problem is to structure fees so

4 For fee arrangements, see Danzon (1983); for adjustments to compensatory damages, see Polinsky and Rubinfeld (1988). One example is given by Geoffrey Miller's (1986) analysis of rule 68 of the Federal Rules of Evidence. Rule 68 specifies that a losing party must pay certain of the winner's court costs. Whether such a move will improve efficiency is naturally formulated in terms of comparing the frequency of trial in two equilibriums-the first with and the second without rule 68 . 
that lawyers provide plaintiffs with accurate information about the value of claims, and the effort lawyers invest in asserting claims increases the expected payoff to plaintiffs to a level commensurate with its costs. When this problem is solved, the client is "well represented." To illustrate, contingent fees have the attractive feature of allowing lawyers to share in the risk of an uncertain claim. Through risk sharing, plaintiffs avoid a situation in which an attorney overstates the value of the claim in order to induce the plaintiff to proceed with it. The principal-agent paradigm has been applied by economists to such problems as labor contracts, executive compensation, and the regulation of public utilities. Unfortunately, the principal-agent model has only recently been applied to lawyers and their clients. ${ }^{5}$

When a claim is made against someone, that person may accept it or contest it. If the claim is contested, the parties will move to the next stage, where they bargain in an attempt to settle their dispute out of court. At this stage, the interests of the two parties to the dispute diverge in part and converge in part. At stake in a civil dispute is a distribution of legal entitlements and liabilities. The interests of the parties diverge because each one wants a larger share of the benefits and a smaller share of the costs, as in divorce bargaining. However, neither party wants to burn up their wealth in a costly dispute. In settlement bargaining, the parties are not enemies or allies but rivals in the sense that their interests converge over an efficient resolution of their dispute and diverge over the distribution of the gains from settlement.

A legal dispute is resolved efficiently when legal entitlements are allocated to the parties who value them the most, legal liabilities are allocated to the parties who can bear them at least cost, and the transaction costs of dispute resolution are minimized. The transfer of an entitlement from someone who values it less to someone who values it more, or the transfer of liability from someone who can bear it at high cost to someone who can bear it at lower cost creates a surplus. Similarly, any reduction in the transaction costs of dispute resolution borne by the parties also creates a surplus.

In settlement bargaining the best strategy for the plaintiff depends on the strategy pursued by the defendant, and vice versa. To illustrate, if the defendant expects the plaintiff to back down and the plaintiff expects the defendant to back down, they may wind up in a frustrating stalemate. The attributes of settlement bargaining-rivalry, communication, side payments, interdependency, and uncertainty-characterize bargaining games as analyzed in economics. The litigation process can be viewed, then, as a bargaining game whose cooperative solution corresponds to a set-

5 Rubinfeld and Sappington (1987) provide one theoretical application and a review of the relevant literature. 
tlement out of court and whose noncooperative solution corresponds to an adversarial trial.

The economic analysis of settlement bargaining tries to predict the frequency and terms of settlement. ${ }^{6}$ Some central conclusions are that settlement is more difficult when threat positions are uncertain, many parties must accept the agreement, and the bargaining game is played only once. More specific conclusions are illustrated by the contrast in rules allocating legal costs. Trials sometimes occur because each party genuinely believes that right is on his side and the court will vindicate him. If each disputant pays his own legal costs (U.S. rule), this tendency of optimism to cause litigations is blunted, whereas the rule of loser-pays-all (British rule) strengthens the tendency of optimism to cause litigation. On the other hand, the British rule increases the stakes in litigation, which discourages it in two ways. First, larger stakes cause the parties to spend more on winning cases that are tried, and the greater expense of trials discourages them. Furthermore, larger stakes cause risk-averse parties to be more eager to avoid trials.

As for the terms of settlement, a useful yardstick is provided by the expected judgment from trial. The expected judgment equals the stakes in dispute discounted by the probability of plaintiff victory. To illustrate, if the stakes in dispute are $\$ 1,000$ and the plaintiff expects to win with probability .5, the expected judgment equals $\$ 500$. It is "reasonable" under certain circumstances for defendant to offer, and plaintiff to accept, the expected judgment as out-of-court settlement. ${ }^{7}$ According to economic theory, the expected judgment is the reasonable settlement if the parties to the legal dispute are symmetrically situated with respect to the costs of proceeding with the dispute. "Symmetry" means that the costs and the timing of them are similar for bringing an action or defending against it. Reasonable settlement in these circumstances on these terms yields the expected outcome of a trial without its costs. If, however, proceeding to trial costs one party more than it costs the other, so that the parties are asymmetrically situated, it is reasonable for the former to make additional concessions toward settlement. To illustrate, when litigation costs the defendant more than it costs the plaintiff, or when the defendant must invest in preparing the case before the plaintiff invests, or when delay in resolving the dispute costs the defendant more than the plaintiff, the reasonable settlement will exceed the expected judgment. An extreme example is provided by nuisance suits in which it is rational for the defendant to settle for a positive sum of

6 See, e.g., P'ng (1983), Shavell (1982), and Perloff and Rubinfeld (1988).

7 "Reasonable" in this context refers to the Nash bargaining solution, in which the parties share the surplus from bargaining equally. 
money, even though the expected judgment is nil and the assertion of the claim is unethical.

Litigation, which is the final stage of a legal dispute, turns rivals into enemies. At trial the parties abandon compromise, and the plaintiff tries to maximize the judgment, while the defendant tries to minimize it. Although settlement bargaining is a positive sum game, litigation is generally viewed as zero sum. In spite of the large literature on zero sum games, the trial process has not been thoroughly modeled by economists.

The four stages in a dispute feed back upon each other. To illustrate, asserting a legal claim (stage 2) presupposes having one (stage 4). In spite of this interdependence, the models of the different stages are conceptually distinct. The "supply" of social harm is modeled in the first stage like the supply of any ordinary commodity. The decision to file a formal complaint is modeled in the second stage as the balancing of costs and benefits by a rational individual, much like any other economic decision. Engaging a lawyer, however, involves a principal-agent model that is a strategic game. Settlement negotiations in the third stage are modeled as a bargaining game. Finally, litigation is modeled in the fourth stage as a zero sum game.

Whatever the emphasis that economists place on a particular theory of dispute resolution, they rely heavily on the concept of equilibrium in their modeling effort. In particular, cross-sectional analyses often assume that a social or economic system is in equilibrium at the time the data are collected. Thus, the economic analysis of law contains many comparisons of the equilibrium effects of different legal rules. ${ }^{8}$ Longitudinal studies, in contrast, can encompass many years during which the legal system undergoes substantial change. It might be thought, consequently, that equilibrium theories are not applicable to longitudinal studies. This is certainly not the case. An equilibrium occurs after a legal or economic system has been shocked and allowed to adjust over time. Changes in the behavior of trial courts over time can be viewed as a series of movements from one equilibrium to another (these are "static equilibria"), with each movement resulting from the shift in one or more exogenous variables. Alternatively, a legal or economic system may achieve a constant rate of growth after it has been shocked by a change in an exogenous variable. ${ }^{9}$ Constant growth rates are also a form of equilibrium. (This is a "dynamic equilibrium.")

8 One example involves the debate as to whether a comparative negligence rule is more efficient than a traditional negligence rule (see, e.g., Haddock and Curran, 1985; Rubinfeld, 1987; Cooter and Ulen, 1986). Another involves the question of whether the British rule in which losing litigants pay litigation costs is more efficient than the U.S. rule in which both sides pay their own costs (Shavell, 1982; Katz, 1988; and Braeutigam et al., 1984).

9 For a discussion of dynamic efficiency, see Landes and Posner (1979) and Blume and Rubinfeld (1982). 
Economists also care about dynamics explicitly-how the economic or legal system evolves as it moves from one equilibrium to another. Thus, a focus on dynamic equilibrium might involve a look at long-term trends, while a focus on dynamics might concentrate on month-to-month or year-to-year changes in important variables. We will see that both approaches have been used implicitly in longitudinal studies of courts.

\section{CRITIQUE OF LONGITUDINAL STUDIES}

The economics literature describes some hypotheses about how law affects litigation rates, which suggest some economic variables to be included in longitudinal studies and predicts their signs. In a fully specified model, litigation rates would be determined in part by variables indicating activity and precaution levels, which in turn would be determined in part by liability rates. To illustrate, the change from negligence to strict liability should reduce the potential plaintiff's precaution and the potential injurer's activity level, while making the injurer's precaution more responsive to the magnitude of damages. Similarly, an increase in the level of damage awards under a rule of strict liability should result in more precaution by injurers.

Litigation rates also depend on victims having a legal right of action and being willing to assert it. An expansion in rights of action and the restructuring of attorney-client relations to facilitate the assertion of claims should result in more claims being asserted. Such changes would include, for example, allowing contingent fees, lawyer advertising, class action suits, and the recovery of attorney's fees by successful plaintiffs.

A full model of litigation rates would also distinguish settlements from trials. The proportion of disputes settled by trial should increase insofar as trial outcomes are less predictable (e.g., the variance in damage awards increases), as when jury's discretion is expanded (e.g., by allowing punitive damages). Similarly, the proportion of trials should increase to the extent that longterm relationships among disputants are replaced by short-term relationships, as when short-run contracts replace franchise agreements.

Litigation tends to cluster at the time the common law changes, which is probably due to uncertainty about the legal entitlements of the parties. Furthermore, the pace of legal innovation may have accelerated, perhaps due to the devaluation of precedent by courts. Whatever the context, the use of equilibrium models forces the researcher to think about the structural variables that should appear as explanatory variables in longitudinal studies. At the same time, one must decide which of the variables are exogenous and which are endogenous; if explanatory variables are endogenous, more sophisticated estimation methods are required. 
These points can be illustrated using some of the articles in this collection.

Now we turn to a critique of the longitudinal studies in this volume in light of our review of economic theories. David Clark's (1990) comparison of litigation trends in Europe and Latin America since 1945 provides a useful example of the types of economic and social models that can be applied in longitudinal studies. Clark's informal examination of the data suggests that different regions within a country have similar time series patterns of litigation rates but differ in the levels of litigation per capita. Clark posits four "hypotheses" that explain the litigation rate data: random, linear, curvilinear, and cyclical. None are structural theories-all simply describe the movements of the time series. Of the four, the "cyclical" hypothesis explains the data the best. This hypothesis is particularly interesting from our perspective because it relies heavily on the equilibrium concepts that have received a great deal of attention from economists.

Clark suggests that litigation in the Spanish regions from 1945 to 1967 or for Italian regions from 1952 to 1968 are best viewed as static equilibria, that is, as adjustments to changing environmental conditions. But he views the rise in litigation in Italy and Spain in the 1970 s as representing dynamic equilibria, in which the rate of growth of litigation is constant. Other than a passing reference to theories of the business cycle and to the Sarat-Grossman (1975) model of the evolution of courts, however, Clark does not pursue in sufficient detail a number of important issues that could be informed by a deeper look at the economic analysis of courts. For example, can the shift from a no-growth static equilibrium to a dynamic growth equilibrium (if this did indeed happen) be explained by changes in the economy that impinge on the existing legal system? Are changes in the economy producing more harmful activity or less precaution? Or is the shift due to changes in the legal system itself? Do more victims have rights of action? Are victims more likely to assert their rights? Are disputes harder to settle, say, because of less predictability in court judgments? Clark points out, for example, that the Italian data include labor cases, while the Spanish data do not. But this in itself doesn't explain the apparent structural shift that took place.

Can the dynamics of the litigation system be explained structurally using socioeconomic variables? (Does, for example, the value that the courts place on precedent change over time, as Blume and Rubinfeld (1982) suggest?) In fact, Clark presents little if any statistical analysis of the dynamic processes underlying his data. Such an analysis would enable him to learn more about any regular stochastic processes that underlie his data series.

The article by Christian Wollschläger (1990) is the longitudinal study that presents the best opportunity to perform a statistical analysis of dynamic processes. Wollschläger's data cover five 
centuries, which is enough time for underlying values to change substantially. Like many of the other longitudinal studies in this collection, however, Wollschläger's focuses on trend (dynamic equilibria), pointing to the overall 1.6 percent rate of litigation growth (without deflating by population) throughout the five-century period in Bremen, Germany. The author gives some reference to the long-wave economic theories but does not pursue the value of a frequency-domain analysis any further. He does note that variation in the amount of litigation was greater in the earlier period compared to more recent times but does not pursue this issue statistically. Of course, Wollschläger does not focus on trend alone. He correctly points to the breaks in the overall patterns of growth and gives some interesting insights into their causes. Unfortunately, he is unable to confront the implications of economic theory directly because he cannot control for changes in the costs of litigation, in the position of the litigating parties, and, more generally, in the business cycle.

It is interesting to note that the conflict perspective presented by political scientist John Stookey (1990) deals explicitly with the economic model. Stookey properly appreciates the endogenous nature of the litigation process. In Stookey's model, social crises affect rates of dispute, which in turn affect the litigation rate. He stresses, however, that the story does not end here. Changes in litigation rates create pressures for policy changes, which in turn induce changes in litigation rates. The complementarity between the approach of the disciplines of political science and economics should be clear. As a political scientist Stookey focuses on the process by which policy changes; an economist would emphasize the effects of those policy changes on the litigation process. ${ }^{10}$

Finally, the article by Van Loon and Langerwerf (1990) fits most naturally into the static equilibrium approach, since it simply correlates various levels of economic activity with civil litigation rates, emphasizing long-term trends. Unfortunately, there are a number of data and methodological problems that make any attempts to test hypotheses uncertain at best. The authors are looking at a substantial number of structural shifts over time. If the static equilibrium approach is appropriate, each of the shifting variables must be exogenous. Yet a crucial variable-the number of advocates-probably is not, since the growth of litigation leads to an increase in the demand for advocates, which probably causes an increase in the supply. A more sophisticated approach (that treats the simultaneity explicitly) is warranted, but the fact that the data are not disaggregated by litigation type may make this im-

10 The endogeneity of litigation rates has obvious statistical implications for researchers who attempt to estimate a structural longitudinal model of the litigation process. Endogeneity requires a simultaneous-equations estimator, which in turn requires a suitable choice of instruments. The theoretical and data demands associated with this view are likely to prove challenging. 
possible. Reports of statistical significance are essentially meaningless here, since significant results merely reflect the fact that pairs of variables are highly trended. If statistical tests are to be taken seriously, differencing or other procedures need to be used to "detrend" the data, and the possibility of lags must be accounted for.

\section{JUDGE-MADE LAW AND THE NORMATIVE MODEL OF LEGAL DISPUTES}

From a private viewpoint, trials are a method of resolving disputes. That is how trials were discussed explicitly in Part I and implicitly in Part II. However, litigation also provides the occasion for judges to interpret or make law. From a social viewpoint, trials are a mechanism of collective choice, which is how they are discussed here.

Some law and economics scholars posit that the common law tends toward efficiency. If this thesis were true, how could it be explained? Two different explanations correspond to two conceptions of the common law. One conception, which regards litigation as a market, views the common law process as driven by competition among rationally self-interested actors. The other conception, which regards judging as an exercise in public reason, views the common law process as driven by the theories of law embraced by judges. Each of these conceptions will be considered in turn.

Several ingenious attempts have been made to explain how competition among litigations, like market competition among businesses, can produce efficiency without anyone consciously aiming for it. ${ }^{11}$ One such mechanism is selective litigation. Suppose that inefficient laws are more likely to be litigated than efficient laws. If inefficient laws are repeatedly challenged in court, they may be overturned, whereas if efficient laws are less frequently challenged, they are more likely to persist unchanged. Selective litigation could work like a strainer that catches inefficient laws while allowing efficient laws to slip past. The residue, being repeatedly sieved, becomes more efficient with the passage of time.

Two assumptions are enough to cause the law to evolve toward efficiency, at least weakly: (1) a rule's efficiency is negatively correlated to the probability that litigants will test it in court, and (2) efficiency is not negatively correlated to the probability of a rule surviving such a test before a judge. ${ }^{12}$ For the process to operate, judges need not favor efficiency, but they must not disfavor it.

Does litigation tend to select inefficient laws? Theory suggests

11 This possibility was first raised by Rubin (1977). See also Priest (1977) and Goodman (1978).

12 A precise statement of the conditions for such evolution is found in Cooter and Kornhauser (1980). 
a weak yes. The more someone values a contested legal entitlement, the more that party will be prepared to spend on litigation to obtain it. This should increase the frequency of court challenges and improve their quality, which, in turn, increases the probability of winning. Thus the value that a person places on a legal entitlement should correlate with the probability of winning it through litigation. By transferring legal entitlements from parties who value them less to parties who value them more, the common law tends toward efficiency.

Although selective litigation is similar to the "invisible hand" in markets, its grip on courts is far weaker. A law is, by its nature, general in the scope of its application, so challenging a law affects everyone who is, or will be, subject of it. Most plaintiffs appropriate no more than a fraction of the value that new precedent creates and redistributes. The effects of a new, more efficient precedent spill far beyond the litigants in the case where it is set. Litigants, however, may have little regard for the social costs that an inefficient rule imposes on others. To illustrate by an extreme example, the active plaintiff in a class action suit may eagerly extinguish the rights of a whole.class of people for the sake of personal gain. ${ }^{13}$ The problem with viewing litigation as a market is that redistributive gains are often more important than inefficiencies in channeling litigation. ${ }^{14}$

The mechanisms discussed so far operate without judges adopting efficiency as a goal. Another possibility is that judges decide cases according to a conception of the public interest that includes efficiency as a norm. First consider the interpretation of legislation. Economists conceive of legislation in a democracy as the product of bargaining among the representatives of various interests, which suggests that statutes should be interpreted according to the terms of the legislative bargain (Easterbrook, 1982). Efficiency is, presumably, an important objective in legislative bargains. An alternative theory of interpretation denies that courts can or should enforce legislative bargains. Instead, courts should interpret statutes exclusively by the language in which they are written (Macey, 1986; Rose-Ackerman, 1988). No politician publicly advocates waste. Consequently, the language of legislation provides some support for efficiency as a norm of interpretation.

Turning from legislation to the common law, some theorists argue that efficiency should be an important or even paramount objective. There is some evidence that the judiciary is giving a

13 See Dam (1975), Rosenfield (1976), and Kornhauser (1983) for some examples.

14 An exception to this pessimistic conclusion concerns laws that are vague. Bargaining games are hard to settle when the parties do not know each others' threat points. See Hoffman and Spitzer (1982). So vague laws cause litigation. Laws whose inefficiency derives from their vagueness will tend to be litigated until inefficiency is diminished by a clear allocation of the underlying entitlements. 
larger role to economic reasoning in its decisions (Easterbrook, 1984). In his pioneering article, Coase argued that court cases should be decided by a careful balancing of costs and benefits. Economically oriented theorists such as Posner (1986), have embraced the cost-benefit theory of adjudication and reached the conclusion that the purpose of common law is maximizing the nation's wealth. This controversial claim has sparked a lively debate. ${ }^{15}$ In opposition, Dworkin (1977, 1980) contends that judges should decide cases on the basis of principles, not policies, and he faults the economic analysis of law for evaluating cases according to the policy of promoting efficiency. For courts to decide a private dispute on grounds of the best public policy would, according to Dworkin, do an injustice to the litigants. In addition, the fact that important legal cases are decided by majority vote of panels of judges raises the possibility that courts are afflicted by the same voting paradoxes as legislatures (Easterbrook 1982; Kornhauser and Sager, 1986; see also Spitzer, 1979, 1980).

Economic theory, based as it is on self-interested choice, has no model of disinterested choice, which is one reason economic models have difficulties explaining the motives of judges. Several ingenious attempts to overcome this difficulty have been made. Private judges (mediators, arbitrators, "rent-a-judges") maximize their own incomes by deciding disputes so as to maximize the demand for their services. If a judge's decisions were not consistent with economic efficiency, a rival judge could lure away all the first judge's customers by offering decisions that both parties preferred (Landes and Posner, 1979; Cooter, 1983). ${ }^{16}$

Some researchers have wondered if perhaps the disinterestedness of public judges is more apparent than real. Judges at the local level are often chosen through contested elections, ${ }^{17}$ and judges at higher levels in some states must be confirmed in uncontested elections. There has been little research and much informal discussion about the consequences of judges having to face the electorate. Federal judges, in any case, seem immune from these pressures, since they are appointed by the president with life tenure. ${ }^{18}$

15 See Hofstra Law Review (1980).

16 For an empirical study of judicial behavior, see Denzau (1979).

17 There is, however, a tendency to return incumbents in judicial elections, and many judges first acquire their position by appointment to complete the term of an elected judge who retires (Bell and Price, 1982).

18 Perhaps, however, judges shape their opinions with promotion within the judiciary in mind. Most lawyers are skeptical of this hypothesis, because promotion, being tied to the vagaries of politics, seems random and unpredictable. Empirical attempts to correlate judicial promotion with attributes of judges' opinions have reached negative conclusions. There is, e.g., apparently no correlation between judges who avoid having their opinions overturned on appeal and judges who get promoted within the federal system (Higgins and Rubin, 1980). 
Understanding their decisions demands a model of disinterested choice.

It is worth noting in passing that the efficiency objective, which dominates the literature, is not the only legal objective susceptible to economic analysis. To illustrate, unfairness can be viewed as a kind of error that the criminal justice system makes as a consequence of having imperfect information. Information is costly for officials to obtain, which is why economics becomes involved in issues of fairness. If resources are allocated inefficiently a more efficient allocation could reduce Type I and Type II errors. Once resources are allocated efficiently, however, it is impossible to reduce one type of error with out increasing another. Economists have a lot to say about such trade-offs.

\section{CONCLUDING COMMENTS}

Statistical explanation of litigation rates, as opposed to statistical description, requires explicit models that make testable predictions. Economists have done a great deal of modeling but little testing, whereas noneconomists have offered statistical descriptions but have not provided theoretical explanations. A combination of improved socioeconomic theory and sound statistical analysis of trial courts is a workable objective. 